\title{
Influência do laser AsGaAl sobre a cartilagem epifisária de ratos
}

Dissertação apresentada à Faculdade de Medicina da Universidade de São Paulo para obtenção do título de Mestre em Ciências

Programa de Pós-Graduação em Ciências da Reabilitação Área de Concentração: Movimento, Postura e Ação Humana

Orientadora: Profa. Dra. Raquel Aparecida Casarotto

São Paulo 


\section{Influência do laser AsGaAl sobre a cartilagem epifisária de ratos}

Dissertação apresentada à Faculdade de Medicina da Universidade de São Paulo para obtenção do título de Mestre em Ciências

Programa de Pós-Graduação em Ciências da Reabilitação Área de Concentração: Movimento, Postura e Ação Humana

Orientadora: Profa. Dra. Raquel Aparecida Casarotto

São Paulo

2009 
Dados Internacionais de Catalogação na Publicação (CIP)

Preparada pela Biblioteca da

Faculdade de Medicina da Universidade de São Paulo

Creprodução autorizada pelo autor

Cressoni, Marcela Dalla Costa

Influência do laser AsGaAl sobre a cartilagem epifisária de ratos / Marcela Dalla Costa Cressoni. -- São Paulo, 2009.

Dissertação(mestrado)--Faculdade de Medicina da Universidade de São Paulo. Departamento de Fisioterapia, Fonoaudiologia e Terapia Ocupacional.

Área de concentração: Movimento, Postura e Ação Humana.

Orientadora: Raquel Aparecida Casarotto.

Descritores: 1.Lasers 2.Terapia a laser de baixa intensidade 3.Crescimento 4.Lâmina de crescimento 5.Ratos Wistar

USP/FM/SBD-152/09 
Aos meus pais, Ivan e Mariangela, que sempre me apoiaram e deram força na minha vida pessoal e profissional. Serei sempre grata a vocês em toda minha vida. Amo vocês. 


\section{AGRADECIMENTOS}

A Deus, por mais uma etapa vencida, pois em todos os momentos da minha vida você sempre esteve comigo.

Aos meus irmãos, Ivanzinho e Dú, sem vocês a minha vida não teria sentido. Obrigada por vocês existirem. Amo vocês.

Ao meu futuro marido e eterno namorado, Bolano, pelo amor e carinho que você sempre me proporcionou. Cresceremos sempre juntos, amo você.

A minha orientadora, Profa. Dra. Raquel Aparecida Casarotto, que mesmo sem me conhecer acreditou em mim e sempre me ajudou em todos os momentos que precisei. Aprendi muito com você nesses anos e por isso the agradeço por essa imensa oportunidade. Jamais Ihe esquecerei. OBRIGADA.

Ao Prof. Dr. Carlos Alberto Anaruma, pela verdadeira amizade. São poucas as pessoas como você: humilde, sincero, amigo, paciente e sempre pronto para ajudar. Não tenho palavras para agradecer tudo que consegui através de você. MUITO OBRIGADA.

A minha querida amiga, mestra, professora e companheira, Helena, que me guiou e me ensinou muitas coisas, tanto na minha vida pessoal quanto profissional. Sempre terei você como espelho e tenha certeza que você e sua família são muito especiais na minha vida.

A minha amiga Patrícia Pereira Alfredo que, mesmo não estando perto, sempre me ajudou em todos os momentos em que precisei. Continue essa pessoa maravilhosa que você é. Sucesso a você, amiga.

Ao Prof. Dr. Antônio Carlos Simões Pião, pela contribuição e paciência com a análise estatística.

À Profa. Dra. Silvia Maria Amado João, pela atenção e sugestões no exame de qualificação.

À Profa. Dra. Renata Hydee Hasue Vilibor, pelas sugestões no exame e na qualificação.

Aos técnicos de histologia da Universidade Estadual Paulista (Unesp) campus Rio Claro, Beto e China, que mais uma vez tiveram imensa paciência e amizade no preparo do minha pesquisa. Sempre contarei com vocês. Obrigada. 
À Unesp campus Rio Claro, que disponibilizou animais, materiais e equipamentos, essenciais ao desenvolvimento deste trabalho.

À Bioset, por ter concedido o aparelho de Laser para a realização desta pesquisa.

As minhas grandes e verdadeiras amigas: Leila, Débora, Gertie e Laura, pela eterna amizade e incentivo.

E a todos os amigos que direta ou indiretamente se envolveram na realização deste trabalho. 
"Se você aproveitar o tempo afim de melhorar-se, o tempo aproveitará você para realizar maravilhas".

(F. Xavier) 
Esta dissertação está de acordo com as seguintes normas em vigor no momento da publicação:

Normalização das referências adaptada de: International Committee of Medical Journal Editors. Uniform requirements for manuscripts submitted to biomedical journals ("Vancouver"). 2005.

Universidade de São Paulo. Faculdade de Medicina. Serviço de Biblioteca e Documentação. Guia de apresentação de dissertações, teses e monografias. Elaborado por Anneliese Carneiro da Cunha, Maria Julia de A. L. Freddi, Maria F. Crestana, Marinalva de Souza Aragão, Suely Campos Cardoso, Valéria Vilhena. 2a ed. São Paulo; 2005.

Abreviaturas dos títulos dos periódicos de acordo com List of journals indexed in Index Medicus. 


\section{SUMÁRIO}

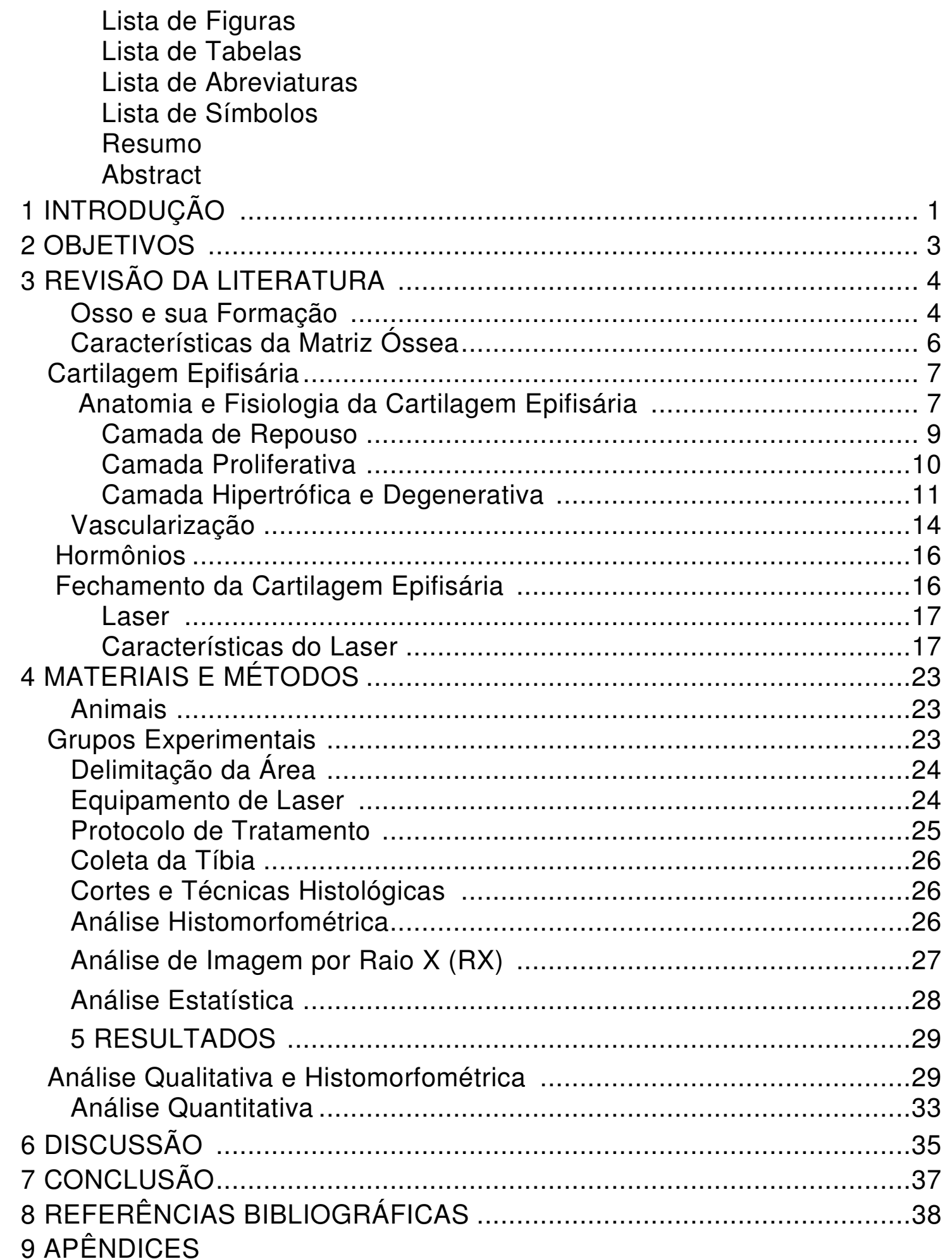




\section{LISTA DE FIGURAS}

Figura 1 - Centro epifisário de ossificação .............................................13

Figura 2 - Molde de cartilagem hialina .................................................15

Figura 3 - Equipamento de Laser utilizado ...........................................24

Figura 4 - Aplicação do Laser AsGaAl 830 nm ........................................25

Figura 5 - Raio X da cartilagem epifisária ....................................................27

Figura 6 - Fotomicrografia da Cartilagem epifisária de ratos do GC (grupo controle) ......................................................................... 31

Figura 7 - Fotomicrografia da Cartilagem epifisária de ratos do grupo G5 (5 Joules) ................................................................ 32

Figura 8 - Fotomicografia da Cartilagem epifisária de ratos do grupo G15 (15 Joules) 


\section{LISTA DE TABELAS}

Tabela 1 - Média e desvio padrão $(\mu \mathrm{m})$ da medida das camadas de cartilagem em repouso

Tabela 2 - Média e desvio padrão $(\mu \mathrm{m})$ do número de condrócitos das camadas de cartilagem 33

Tabela 3 - Média e desvio padrão da espessura final e inicial da cartilagem epifisária e comprimento final da tíbia 


\section{LISTA DE ABREVIATURAS}

Laser - Light Amplification by Stimulated Emission of Radiation

Raio X - RX

HILT - Hight-Intensity-Laser Treatment

LILT - Low-Intensity Laser Treatment

DP - Densidade de Potência

DE - Densidade de Energia

UNESP - Universidade Estadual Paulista "Júlio de Mesquita Filho"

GC - Grupo Controle

G5J - Grupo 5 Joules

G15J - Grupo 15 Joules 


\section{LISTA DE SÍMBOLOS}

$\mathrm{J}$ - Joules

$\mathrm{cm}^{2}$ - Centímetro ao quadrado

$\mathrm{PO}_{2}$ Pressão de Oxigênio

mmHg - Milímetro de Mercúrio

C - Celsius

$\mu$ - Micrômetro

mm - Milímetro

AsGaAl - Arsenieto de Gálio Alumínio

ATP - Trifosfato de Adenosina

HE - Hematoxilina Eosina

Ca - Cálcio

K - Potássio 


\section{RESUMO}

Cressoni MDC. Influência do Laser AsGaAl sobre a cartilagem epifisária de ratos [dissertação]. São Paulo: Faculdade de Medicina, Universidade de São Paulo; 2009. 45p.

Objetivo: Estudar o efeito das diferentes doses $\left(5 \mathrm{~J} / \mathrm{cm}^{2}\right.$ e $\left.15 \mathrm{~J} / \mathrm{cm}^{2}\right)$ do Laser Diodo de $830 \mathrm{~nm}$ na cartilagem epifisária de ratos, analisando o comprimento do osso, a espessura e o número de condrócitos de cada camada da cartilagem epifisária. Materiais e Métodos: 30 ratos da linhagem Wistar, machos, pesando em média $\pm 280 \mathrm{~g}$, com 23 dias de idade, divididos aleatoriamente em 3 grupos: Grupo Controle (GC), Grupo (G5) - dose de $5 \mathrm{~J} / \mathrm{cm}^{2}$, grupo 15 (G15) - dose de $15 \mathrm{~J} / \mathrm{cm}^{2}$. Foram realizadas 10 aplicações do Laser AsGaAl $830 \mathrm{~nm}$ em dias alternados. Os animais foram sacrificados 24 horas após a última aplicação, no $21^{\circ}$ dia após a primeira aplicação, com dose letal de $200 \mathrm{mg} / \mathrm{Kg}$ de pentobarbital sódico. As lâminas foram coradas com H/E (Hematoxilina Eosina). Realizou-se a documentação fotográfica das lâminas em fotomicroscópio ZEISS e, posteriormente, análise histomorfométrica e análise histológica. Para a análise estatística utilizou-se o teste de variância fatorial One-Way ANOVA com nível de significância considerado significativo para $\alpha<0,05$, seguido pelo teste de Tukey. Resultados: A cartilagem epifisária demonstrou através da análise histológica e pela imagem do $R X$ aumento da espessura da cartilagem epifisária e aumento no número de condrócitos dos grupos G5 e G15. Conclusão: O Laser de AsGaAl 830 $\mathrm{nm}$, dentro dos parâmetros utilizados nesta pesquisa, pode causar alteração na espessura da cartilagem epifisária, aumento no número de condrócitos, porém não é suficiente para causar qualquer alteração no comprimento final do osso.

Descritores: Lasers, Terapia a Laser de baixa intensidade, Lâmina de crescimento, crescimento, ratos Wistar. 


\section{ABSTRACT}

Cressoni MDC. Influência do Laser AsGaAl sobre a cartilagem epifisária de ratos [dissertação]. São Paulo: Faculdade de Medicina, Universidade de São Paulo; 2009. 45p.

Objective: To study the effect of an 830-nm GaAlAs diode Laser at two different energy densities $\left(5 \mathrm{~J} / \mathrm{cm}^{2}\right.$ and $\left.15 \mathrm{~J} / \mathrm{cm}^{2}\right)$ on the epiphyseal cartilage of rats, by evaluating the bone length, and the number of chondrocytes and thickness of each zone of the epiphyseal cartilage. Materials and Methods: A total of 30 male Wistar rats with 23 days of age and weighing $280 \mathrm{~g}$ on average were randomly divided into 3 groups: control group (CG, no stimulation), G5 group (energy density, $5 \mathrm{~J} / \mathrm{cm}^{2}$ ), and G15 group (energy density, $15 \mathrm{~J} / \mathrm{cm}^{2}$ ). Laser treatment sessions were administered every other day for a total of 10 sessions. The animals were euthanized 24 hours after the last treatment session (21 days after the first application) with a lethal dose of sodium pentobarbitone $(200 \mathrm{mg} / \mathrm{kg}$ ). Histological slides of the epiphyseal cartilage were stained with hematoxylin-eosin (HE), photographed with a Zeiss photomicroscope, and subjected to histometric and histological analyses. Statistical analysis was performed using one-way analysis of variance (ANOVA) followed by Tukey's post-hoc test. All statistical tests were performed at a significance level of 0.05 . Results: Histological analysis and x-ray radiographs revealed an increase in thickness of the epiphyseal cartilage and in the number of chondrocytes in the G5 and G15 groups. Conclusion: The 830-nm GaAlAs diode Laser, within the parameters used in this study, induced changes in the thickness of the epiphyseal cartilage and increased the number of chondrocytes, but it was not sufficient to induce changes in bone length.

Key words: Lasers, Laser therapy low-level, growth plate, growth, rats wistar. 


\section{INTRODUÇÃO}

Conhecer a formação, o crescimento e a maturação do osso é de fundamental importância para os profissionais que atuam na área da saúde.

No osso longo há dois sítios de crescimento, localizados nas suas extremidades, denominados placa de crescimento, os quais proporcionam crescimento em comprimento do osso longo (Gomes e Volpon, 1991).

A placa de crescimento possui diferentes denominações na literatura, como cartilagem de conjugação, cartilagem de crescimento, disco epifisário e epífise de crescimento (Gomes e Volpon, 1991), sendo três os fatores responsáveis pela coordenação do desenvolvimento e do crescimento pós-natal: influências ambientais, fatores de crescimento e controle genético (lannotti, 1990).

Segundo Salter e Harris (1963), as lesões sobre a epífise de crescimento representam $15 \%$ a $20 \%$ das fraturas em criança e, além disso, a placa de crescimento está relacionada anatomicamente a outras estruturas, como tendões, bursas e ligamentos.

A epífise de crescimento situa-se entre o tecido ósseo das epífises e o da diáfise. Seu desaparecimento, por ossificação, determina a parada do crescimento longitudinal do osso (lannotti, 1990). Alguns recursos eletroterapêuticos estudados, como o ultra-som, as forças mecânicas e os campos eletromagnéticos (Wiltink et al., 1995; Kenwright e Goodship, 1989; Nepola et al., 2000; Pilla et al., 1990), podem atingir de forma direta ou indireta a cartilagem epifisária. Existem poucos estudos sobre a influência destes recursos sobre a cartilagem epifisária. A laserterapia de baixa intensidade inclui-se neste rol de recursos que necessitam ser avaliados quanto a possibilidade de aplicação nestas epífises (Cheetham et al., 1992). 
O Laser é a abreviatura da expressão inglesa Light Amplification by Stimulated Emission of Radiation, que significa amplificação de luz por emissão estimulada de radiação (Low e Reed, 2001), e, embora seja utilizado desde 1965 em áreas médicas e paramédicas, seus efeitos e aplicações ainda vêm sendo pesquisados (Brugnera e Pinheiro, 1998).

O Laser de baixa intensidade tem demonstrado produzir modificações morfológicas sobre diferentes estruturas, como alterações da síntese de RNA, incremento na vascularização (Luger et al., 1998), efeitos positivos na proliferação celular (Nicolau, et al., 2003), diferenciação e calcificação de clones de células osteobláticas (Karu, 2003). Estas modificações ocorrem através do efeito da fotobiomodulação, que pode estimular ou inibir o tecido-alvo submetido à aplicação da Laserterapia (Tam, 1999), de modo que as respostas desencadeadas pelo Laser nos tecidos biológicos estão relacionadas ao comprimento de onda, à quantidade de energia liberada no tecido, ao número de aplicações, ao intervalo de tempo, entre outros (Coombe e Hunter, 2001; Gur et al., 2003).

É válido lembrar, no entanto, que o Laser utilizado na fisioterapia não apresenta potencial destrutivo, uma vez que as radiações emitidas apresentam potência inferior a 1W (Karu, 2003).

Diversos autores indicam o uso do Laser em crianças (Reed e Low 1997; Navratil e Kymplova, 2002; Baxter, 2003). Estes autores baseiamse no estudo de Cheetham et al. (1992), que utilizou a dose de $5 \mathrm{~J} / \mathrm{cm}^{2}$ três vezes por semana e analisou a epífise no $6^{\circ}$ e $12^{\circ}$ dias de aplicação, mostrando que esta dose não foi significativa para alterar a estrutura da cartilagem epifisária.

Uma vez que diferentes parâmetros dosimétricos podem não produzir os mesmos efeitos fotobiomodulatórios, é necessário variar estes parâmetros a fim de demonstrar a possibilidade de irradiação segura sobre as epífises de crescimento (Tam, 1999). 


\section{OBJETIVO}

Embora o Laser venha sendo utilizado na prática clínica no que se refere à cicatrização, à analgesia, à ação antiinflamatória, entre outros, existem poucos estudos verificando seus efeitos em crianças. Assim, o objetivo geral deste estudo é verificar o efeito das diferentes doses do Laser diodo de $830 \mathrm{~nm}$ na cartilagem epifisária de ratos $\left(5 \mathrm{~J} / \mathrm{cm}^{2}\right.$ e 15 $\left.\mathrm{J} / \mathrm{cm}^{2}\right)$.

Os objetivos específicos deste estudo são:

- Analisar o comprimento do osso e a espessura da cartilagem através da imagem do Raio X (RX).

- Mensurar a espessura e o número de condrócitos de cada camada da cartilagem epifisária através da análise qualitativa e histomorfométrica.

- Comparar e interpretar as diferenças apresentadas entre o grupo Controle e Tratado com $5 \mathrm{~J} / \mathrm{cm}^{2}$ e $15 \mathrm{~J} / \mathrm{cm}^{2}$. 


\section{REVISÃO DE LITERATURA}

Osso e sua Formação

Os ossos representam a estrutura básica de sustentação e proteção dos órgãos do corpo, incluindo o cérebro e a medula, e das estruturas no interior da cavidade torácica, principalmente os pulmões e o coração. Servem como apoio mecânico, pois permitem a locomoção e a multiplicação da força dos músculos para a realização dos movimentos corporais. Atuam também como reservatório para muitos minerais do corpo, visto que armazena cerca de $99 \%$ do cálcio do organismo (Stevens e Lowe, 1997).

Segundo Gartner e Hiatt (1999), o osso é composto por células de sustentação (osteoblastos e osteócitos); matriz não mineralizada de colágeno e glicosaminoglicanas (osteóide); sais minerais inorgânicos depositados na matriz e células remodeladoras (osteoclastos).

O osteóide é um tecido de sustentação colágenoso formado principalmente de colágeno tipo I, infiltrado em um gel de glicosaminoglicanas que contem glicoproteínas específicas como a osteocalcina, a qual se liga fortemente ao cálcio, permitindo ao osso sua força mecânica e rigidez. Os osteoclastos e osteócitos, por sua vez, produzem e nutrem o osteóide, onde os sais inorgânicos são depositados (Dângelo e Fattini, 1997).

A face externa dos ossos é recoberta pelo periósteo, camada externa de tecido conjuntivo fibroso e denso, e a camada interna contem células osteoprogenitoras (osteogênicas). A cavidade central do osso é revestida pelo endósteo, constituído por uma única camada de células osteoprogenitoras e de osteoblastos (Stevens e Lowe, 1997).

No corpo humano os ossos são formados por um processo de ossificação intramembranosa, que ocorre no centro de uma membrana 
conjuntiva, ou por um processo chamado ossificação endocondral, que se inicia sobre uma peça de cartilagem hialina de forma semelhante ao osso a ser formado. As diferenças destes dois processos aparecem morfologicamente pela estrutura física do osso, ou seja, os ossos formados a partir de membranas são achatados como os ossos do crânio e maxilar; já os ossos formados a partir de cartilagens são curtos e longos (Junqueira e Carneiro, 1999).

Segundo Irving (1973), a ossificação intramembranosa ocorre num tecido mesenquimal ricamente vascularizado, onde as células mesenquimais diferenciam-se em osteoblastos, que secretam matriz óssea formando uma rede de espículas e trabéculas ósseas, em forma de esponja, sendo o tecido conjuntivo vascular no seu interior transformando-se em medula óssea. A adição de trabéculas à periferia aumenta o tamanho do osso em formação.

Já na ossificação endocondral forma-se um pequeno molde de cartilagem hialina, que continua a crescer e serve como base para 0 crescimento do osso, de modo que quando esta cartilagem é reabsorvida o osso maduro a substitui. Os condrócitos, células cartilaginosas, hipertrofiam, acumulam glicogênio em seu citoplasma e se tornam vacuolados. A hipertrofia dos condrócitos resulta no crescimento de suas lacunas e redução dos septos de matriz cartilaginosa (Derrickson e Tortora, 2005).

Nos dois processos, o primeiro tecido ósseo formado é do tipo primário, ou seja, apresenta fibras colágenas sem organização definida e com menor teor de minerais, sendo aos poucos substituído pelo tecido ósseo secundário, que continua sendo reabsorvido ao longo da vida, embora mais lentamente. Este é caracterizado por fibras colágenas organizadas, paralelas umas as outras, ou em camadas concêntricas em torno de canais com vasos, formando, assim, o sistema de Havers (Junqueira e Carneiro, 1999). 
O sistema de Havers é constituído por um tubo longo, às vezes ramificado, formado por lamelas ósseas concêntricas. No centro deste tubo existe o canal de Havers, que contém vasos, nervos e tecido conjuntivo. Estes canais comunicam-se entre si com a cavidade medular e com a superfície externa do osso por meio de canais transversais ou oblíquos chamado canais de Volkmann, que se diferenciam dos canais de Havers pela ausência de lamelas ósseas concêntricas (Marieb e Hoehn, 2007).

Dessa forma, todos os canais vasculares encontrados no tecido ósseo aparecem quando a matriz óssea se forma ao redor de vasos préexistentes (Stevens e Lowe, 1997).

\section{Características da Matriz Óssea}

A parte óssea inorgânica representa cerca de $50 \%$ do peso da matriz óssea e $65 \%$ de seu peso seco. É possível dizer que os íons mais encontrados são o fosfato e o cálcio, que juntos formam cristais de hidroxipatita, e, consequentemente, a associação destes cristais com fibras colágenas é responsável pela dureza e resistência do tecido ósseo. Na parte inorgânica há também bicarbonato, magnésio, potássio, sódio e citrato em pequenas quantidades (Douglas, 2006).

A parte orgânica da matriz é formada por fibras colágenas (95\%), constituídas de fibras de colágeno do tipo I e por pequena quantidade de substância fundamental amorfa que contém proteoglicans e glicoproteínas (Dallemagne e Fabry, 1956).

As glicoproteínas também estão presentes na matriz óssea, e dentre elas estão a osteocalcina e a osteopontina, que se ligam à hidroxipatita. De acordo com Gartner e Hiatt (1999), a vitamina D estimula a síntese destas glicoproteínas. 
Considerando que o osso compacto contém aproximadamente $30 \%$ da matriz e 70\% de sais (Kaplan et al., 1994), pode-se dizer que a rigidez da matriz orgânica é aumentada pelos depósitos de sais de cálcio.

As fibras colágenas, presentes na matriz orgânica, estendem-se em todas as direções do osso principalmente ao longo das linhas de força, as quais vão proporcionar ao osso sua força elástica. Assim, enquanto essas fibras, bem como os tendões, apresentam uma grande resistência à tensão, os sais de cálcio possuem uma grande resistência à compressão. Dessa forma, essas propriedades combinadas fornecem à estrutura óssea um alto grau de resistência à tensão e à compressão (Kaplan et al., 1994).

A remoção do cálcio torna o osso flexível, sem interferir na sua forma; porém, a destruição da parte orgânica, principalmente do colágeno, deixa o osso intacto, mais quebradiço, o que é comum nos casos de ossos osteoporóticos (Silva, 1994).

\section{CARTILAGEM EPIFISÁRIA}

Anatomia e Fisiologia da Cartilagem Epifisária

A cartilagem epifisária é um tecido avascular que contém células arredondadas separadas por uma matriz predominantemente basófila. As células da cartilagem, os condrócitos, produzem uma matriz extracelular constituída principalmente por fibrilas de colágeno tipo II e por grandes proteoglicanos agregantes; em menores quantidades são encontrados outros tipos de colágeno e proteínas não colagênicas (Gartner e Hiatt, 2002). 
Existem diferentes tipos de cartilagens, principalmente no que se refere à composição e organização dos componentes da sua matriz extracelular. Durante o desenvolvimento, os ossos longos são precedidos por um modelo cartilaginoso, o qual possui uma parte média estreitada e as extremidades dilatadas, correspondendo, assim, à diáfise e à epífise do osso. O primeiro tecido a aparecer é formado por ossificação intramembranosa do pericôndrio, que recobre a parte média da diáfise formando um cilindro ósseo oco (Guyton e Hall, 1997).

As células cartilaginosas envolvidas pelo cilindro ósseo hipertrofiam e a matriz da cartilagem se mineraliza, fazendo com que os condrócitos morram. Partindo do periósteo, os vasos sanguíneos atravessam o cilindro e penetram na cartilagem calcificada levando células osteogênicas, as quais se proliferam e se diferenciam em osteoblastos (Kaplan et al., 1997).

Após a diferenciação ocorre a formação de camadas contínuas nas superfícies dos tabiques cartilaginosos calcificados, iniciando-se a síntese da matriz óssea que logo se mineraliza, ocorrendo a formação do tecido ósseo primário sobre os restos da cartilagem calcificada (Guyton e Hall, 1997).

O centro de ossificação, também chamado de centro primário, cresce em sentido longitudinal, em direção às epífises, e desde o início de sua formação surgem os osteoclastos, e ocorre a absorção do tecido ósseo formado no centro da cartilagem, aparecendo assim o canal medular (Gartner e Hiatt, 2002).

À medida que o canal medular cresce, as células sanguíneas (originadas de células hematógenas multipotentes) são trazidas pelo sangue e mais tarde são formados os centros de ossificação secundário, um em cada epífise, porém não simultaneamente; e seu crescimento é radial em vez de longitudinal (Guyton e Hall, 1997).

Quando o tecido ósseo formado nos centros secundários ocupa a epífise, o tecido cartilaginoso fica reduzido a dois locais: cartilagem 
articular, a qual persistirá por toda a vida, e a cartilagem epifisária ou de conjugação, constituída por um disco cartilaginoso responsável pelo crescimento longitudinal do osso (Junqueira e Carneiro, 1995).

Nesta cartilagem distinguem-se as seguintes partes a partir da epífise: camada de repouso, camada proliferativa, camada hipertrófica e camada degenerativa, as quais são essenciais para o crescimento longitudinal do osso e a formação de osso endocondral (Peterson, 1984).

Camada de Repouso

Vários termos diferentes têm sido aplicados a esta camada, incluindo camada de descanso, camada de cartilagens pequenas e camada germinal (Peterson, 1984).

A camada de repouso é adjacente à epífise óssea, e suas células são esféricas, únicas ou em pares, apresentando-se relativamente em pouca quantidade quando comparada ao número de células das outras camadas. Tais células são separadas uma das outras por matriz extracelular, estocando lipídios e outros materiais. Além disso são mantidas em reserva para mais tarde servirem a outras exigências nutricionais (lannotti, 1990).

De acordo com Peterson (1984), as células demonstram na microscopia eletrônica abundante retículo endoplasmático e sintetizam proteína ativamente. Além disso, elas demonstram mais vacúolos de lipídios do que as células de outras camadas; no entanto contêm menos glucose-6-fosfato-dehidrogenase e dehidrogenase láctica. Também apresentam quantidade mais baixa de fosfatase alcalina e ácido fosfato total e inorgânico, cálcio, potássio e magnésio.

Na presença de mucopolissacarídeo neutro ou de proteoglicanos agregados a matriz mostra uma reação histoquímica positiva, e a tensão de oxigênio do espaço extracelular nas camadas difíceis da epífise de 
crescimento revela que o $\mathrm{PO}_{2}$ é mais baixo que $20,5 \pm 2.1 \mathrm{mmHg}$, o que significa que os vasos sanguíneos que passam por essa camada em canais de cartilagem para irrigar o topo da camada proliferativa não suprem a própria camada de reserva (Brighton et al., 1969).

Uma vez que os condrócitos da camada de reserva não se proliferam continuamente (ou tampouco esporadicamente), é possível dizer que essa camada não é germinativa. Na realidade a sua função está relacionada com o alto teor de lipídio e vacúolo, de modo que armazenam materiais para exigências nutricionais posteriores e, neste sentido, a função da camada de reserva é de estocagem (lannotti, 1990).

Camada Proliferativa

Os condrócitos esféricos sozinhos ou em pares abrem espaço para os condrócitos achatados nas camadas proliferativas, as quais estão alinhadas em colunas longitudinais. As células do topo de cada coluna é a verdadeira célula cartilaginosa (mãe), de modo que o começo ou o topo da camada de proliferação é a verdadeira camada germinativa da epífise de crescimento (Bright, 1982).

O crescimento longitudinal da epífise é igual à taxa de produção de novos condrócitos no topo da camada de proliferação se multiplicada pelo tamanho máximo dos condrócitos na parte de baixo da camada hipertrófica (Bright, 1982).

Kember (1960) demonstrou que 5 foi o número médio dos poucos condrócitos produzidos diariamente em cada coluna celular da epífise de crescimento na tíbia proximal dos ratos. Como o diâmetro médio dos condrócitos na parte de baixo da camada hipertrófica é de $30 \mu$, a taxa de crescimento dessa epífise em particular é de $150 \mu$ por dia. Kember também calculou que cada divisão das células do topo da coluna celular contribui com 29 células, o que significa que cada divisão da célula do 
topo contribui, na realidade, com $0.9 \mathrm{~mm}$ de crescimento longitudinal na tíbia do rato $(29 \times 30 \mu=870 \mu)$. Dessa forma, 70 ou 50 divisões da célula do topo seriam necessárias para completar o crescimento da tíbia do rato. É possível dizer que esses princípios (não os números absolutos) são presumivelmente verdadeiros para a epífise de crescimento humano.

$\mathrm{Na}$ camada de proliferação, a matriz contém aproximadamente a mesma quantidade de fibras de colágeno encontradas na camada de reserva. A matriz apresenta reação histoquímica positiva para mucopolissacarídeos neutros ou proteoglicanos agregados (lannotti, 1990).

A tensão do oxigênio é mais alta $(57.0 \pm 5.8 \mathrm{mmHg})$ do que em qualquer outra camada da epífise de crescimento, o que se deve ao rico suprimento vascular presente no topo da camada (Brighton et al., 1969).

As funções destas camadas são: produção de matriz, proliferação celular. A combinação dessas duas funções se iguala ao crescimento linear ou longitudinal do osso. Essa condrogênase ou crescimento cartilaginoso é o único responsável pelo aumento do crescimento linear de qualquer osso, e a porção cartilaginosa da epífise não aumenta de comprimento (Kimmel e Webster, 1980).

Camada Hipertrófica e Degenerativa

Os condrócitos achatados na camada proliferativa tornam-se esféricos e bastante aumentados na camada hipertrófica. Essas mudanças na morfologia celular são bastante abruptas e podem determinar o final da camada proliferativa e o começo da camada hipertrófica. O condrócito médio atinge o final da camada hipertrófica, aumentando cerca de 5 vezes o tamanho que tinha na camada proliferativa (Kimmel e Webster, 1980). 
A tensão de oxigênio na camada hipertrófica é bastante baixa (24.3 $\pm 2.4 \mathrm{mmHg}$ ), o que se deve a não vascularização desta camada. No final da camada hipertrófica o glicogênio está completamente reduzido, e nesta área de baixa tensão de oxigênio não existe outra fonte de nutrição que sirva de energia para a mitocôndria. Como a retenção de cálcio pela mitocôndria é um processo ativo, isto é, requer energia, assim que o suprimento de glicogênio dos condrócitos são exauridos, a mitocôndria libera cálcio, sendo um fator importante na calcificação da matriz (Brighton et al., 1969).

Diferente das outras camadas, a matriz da camada hipertrófica apresenta reação histoquímica positiva para um ácido mucopolissacarídeo desagregado. A degradação do proteoglicano provavelmente deve ocorrer em função das enzimas lissosomiais, uma vez que os condrócitos na camada hipertrófica contêm concentração de lissosomas mais alta do que nos condrócitos de qualquer outra camada da epífise (Kimmel e Webster, 1980).

De qualquer forma, a calcificação inicial na epífise de crescimento ocorre dentro ou sobre as vesículas da matriz, as quais estão presentes no septo longitudinal (Kimmel e Webster, 1980).

A calcificação inicial pode ocorrer na forma de fosfato de cálcio amorfo, com o crescimento e a confluência do cristal, o septo longitudinal se torna calcificado, e isso ocorre na porção inferior da camada hipertrófica, uma região frequentemente chamada de camada de calcificação provisional (Peterson, 1984).

As vesículas da matriz são estruturas muito pequenas (de 1000 a 1500 angstroms de diâmetro) que são envolvidas numa membrana trilamelar, sendo, portanto, produzidas por condrócitos, os quais ocorrem em maior concentração na camada hipertrófica. As vesículas da matriz são ricas em fosfatase alcalina, e essa enzima pode agir como uma pirofosfatase, outro inibidor da precipitação da fosfatase de cálcio. As vesículas da matriz começam a acumular cálcio no meio da camada 
hipertrófica, na qual a mitocôndria começa a perder cálcio. Isto é uma evidência circunstancial que indica que o cálcio mitocondrial está envolvido na calcificação inicial que ocorre na epífise de crescimento (Brighton et al., 1969).

Dessa forma, as funções da camada hipertrófica e degenerativa são: preparar a matriz para a calcificação e calcificar a matriz (Brighton et al., 1969).

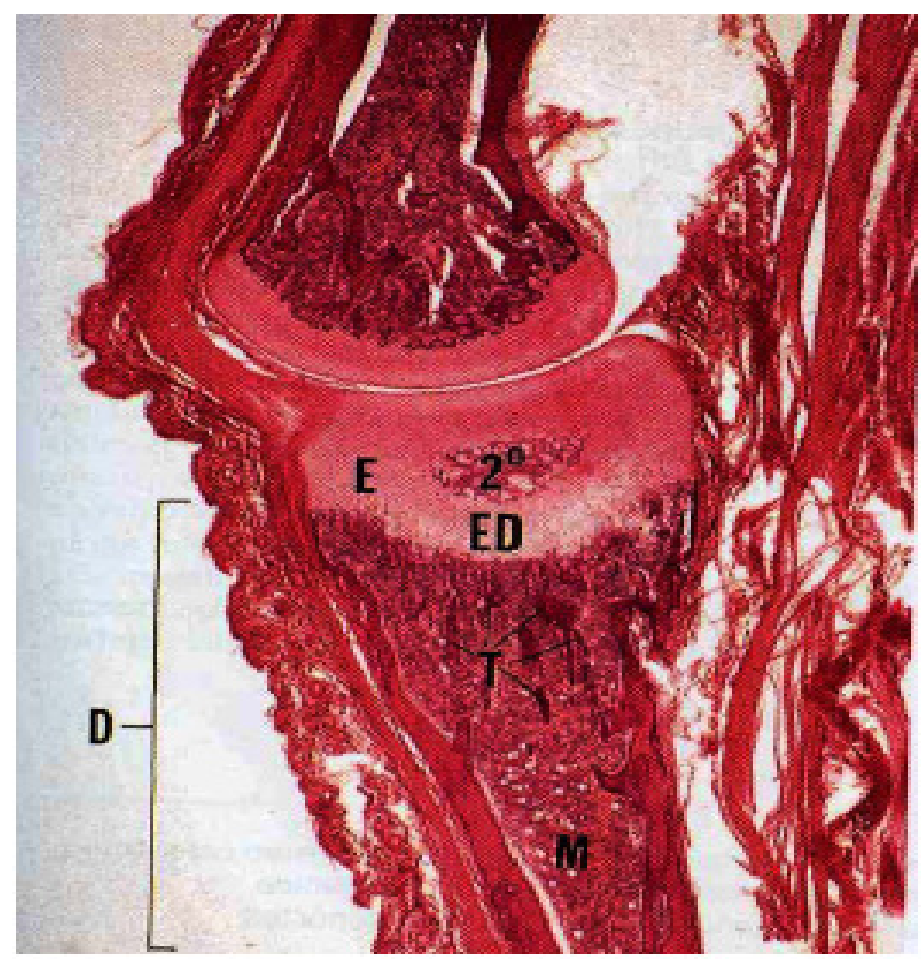

Figura 1 - Centro epifisário de ossificação Macaco, Corte parafina 14X. Nessa fotomicrografia em pequeno aumento, a diáfise (D) da falange distal foi substituída por osso, e a cavidade medular é preenchida por medula (M). A epífise (E) da mesma falange está sofrendo ossificação através do centro secundário de ossificação $\left(2^{\circ}\right)$, estabelecendo, assim, a placa epifisária (ED). As trabéculas (T) estão perfeitamente evidentes na face disfisária da placa epifisária (Gartner e Hiatt, 2002). 
Vascularização

Os vasos epifisários, pericondrais e metafisários são os responsáveis pela fonte de nutrição da cartilagem epifisária (Schott e Gameiro, 2003).

Os vasos epifisários penetram através do osso subcondral e fornecem suprimento para a zona de repouso, de modo que a viabilidade da placa epifisária está na dependência da nutrição recebida por esses vasos, e, no caso de interrupção, haverá bloqueio da proliferação celular e, consequentemente, parada do crescimento e fechamento da placa epifisária.

Os vasos pericondrais constituem o anel pericondral e são uma extensão da vascularização periosteal, sendo responsáveis pela nutrição das porções periféricas das placas epifisárias. É raro que uma separação epifisária determine a interrupção desses vasos, uma vez que o periósteo envolve a metáfise (Brighton, 1987).

Os vasos metafisários são uma extensão da artéria nutrícia do osso e determinam a ossificação endocondral, trazendo as células endoteliais que se transformam em osteoblastos. Na hipótese da lesão dessas células a placa continuará a crescer e, se não ocorrer ossificação adequada do lado metafisário, ficará alargada (Iannotti, 1990). 


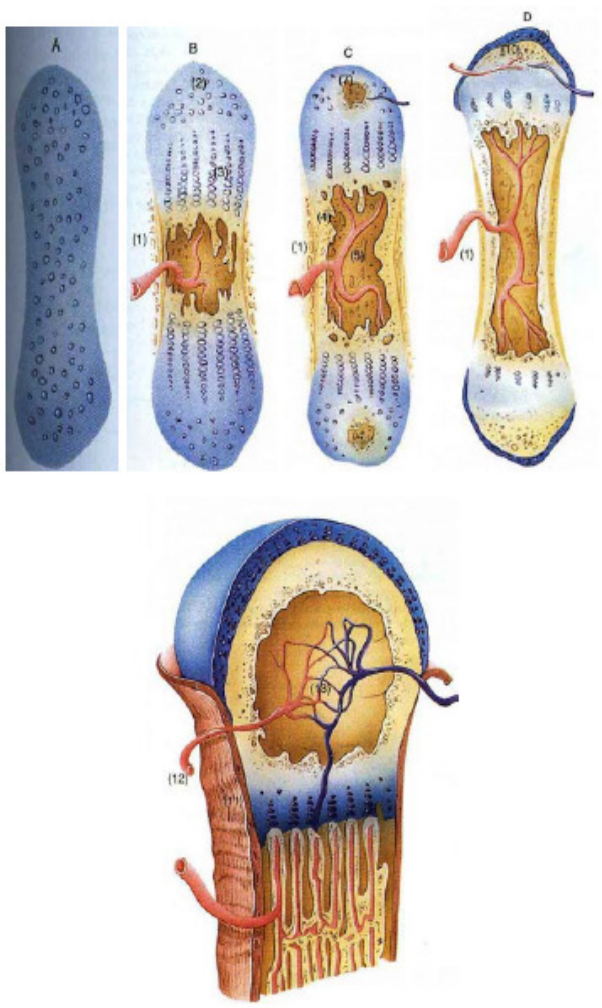

Figura 2 - (A) Molde de cartilagem hialina. (B) A vascularização do pericondrio resulta nas transformações das células osteogênicas, formando um colar ósseo subperiosteo (1) através da ossificação intramembranosa, que rapidamente se torna perfurado pela atividade osteoclástica. Condrócitos no centro da cartilagem hipertrofiada (3), e suas lacunas confluentes (C). Aumento do comprimento e largura do colar ósseo subperiósteo (1), as lacunas confluentes são invadidas por um broto periósteo (4) e a cavidade osteoclástica forma uma cavidade medular primitiva (6), cujas paredes são constituídas por um complexo de cartilagem calcificada. As epífises mostram os inícios dos centros de ossificação secundária (7) (D) e (E). O colar ósseo subperiósteo (1) se torna suficientemente grande para sustentar o osso longo em desenvolvimento, de tal forma que muito da cartilagem é reabsorvida, com exceção da placa epifisária (8) e o revestimento das epífises (9). A ossificação das epífises ocorre a partir do centro (10), de modo que o periósteo vascular (11) não recobre a superfície cartilaginosa. Os vasos sanguíneos (12) penetram nas epífises sem vascularizar a cartilagem, constituindo a rede vascular (13) ao redor da qual o osso esponjoso será formado (Gartner e Hiatt, 2002). 
HORMÔNIOS

Durante o crescimento do esqueleto existem alterações normais na cartilagem epifisária, as quais ocorrem várias vezes durante a vida da criança.

A tiroxina (T4), a triiodotironina (T3), a calcitonina (secretada pela glândula tireóide), o paratormônio (secretada pela glândula paratireóide), os glicocorticóides e os esteróides sexuais (glândulas supra-renais) e a insulina (secretada pelas ilhotas de Langerhans do pâncreas) são os hormônios com ação na cartilagem epifisária (Junqueira e Carneiro, 1995).

A ação do hormônio de crescimento resulta de múltiplos efeitos sobre o osso com a deposição aumentada de proteínas pelas células condrócitas e osteogênicas, que causam crescimento no osso, aumento da taxa de reprodução dessas células e têm efeito específico da conversão dos condrócitos em células osteogênicas, causando, assim, a deposição de novo osso (Guyton e Hall, 1997).

Fechamento da Cartilagem Epifisária

$\mathrm{Na}$ segunda ou terceira década de vida do ser humano ocorre a fusão entre os centros das epífises e diáfises, de modo que no sexo feminino ocorre mais cedo em relação ao sexo masculino. $O$ úmero serve como índice esquelético das transições para a adolescência e vida adulta, em função de a sua epífise distal ser a primeira, dentre os ossos longos, a se unir, sendo sua epífise proximal a última (lannotti, 1990).

Vaquero e Suarez (1999) relatam que a epífise distal do fêmur é a maior do esqueleto e a que suporta um crescimento mais rápido, sendo responsável por $70 \%$ do crescimento longitudinal do fêmur, e de $37 \%$ do crescimento longitudinal total de todo membro inferior. É responsável 
também pelo crescimento de um centímetro a cada ano até chegar na idade adulta. A fusão com a metáfise ocorre entre a idade de 14 e 16 anos nas meninas, e de 16 a 18 anos nos meninos.

A extremidade proximal da tíbia possui dois núcleos de ossificação: o principal está situado na porção central epifisária e o secundário localizado na parte distal da tuberosidade da tíbia. O centro de ossificação da tuberosidade faz fusão com a epífise proximal nos indivíduos com 17 anos de idade. O fechamento da epífise localizada na parte distal se encerra na idade de 13 a 15 anos nas mulheres e de 15 a 19 nos homens. A epífise proximal da tíbia contribui em 55\% no crescimento longitudinal da tíbia, e $25 \%$ do crescimento total da perna, sendo responsável por 0,6 centímetros de crescimento longitudinal por ano. As cartilagens de crescimento situadas na região do joelho são responsáveis por mais de $60 \%$ do crescimento longitudinal da extremidade inferior (Vaquero e Suarez, 1999).

LASER

Características do Laser

O uso do Laser vem crescendo bastante nas últimas duas décadas nas mais diversas áreas, como medicina, odontologia, fisioterapia. Porém, o conhecimento de seu funcionamento ainda é deficiente pelos profissionais da área da saúde.

O Laser passou a ser utilizado no Brasil a partir da segunda metade da década de 1980, o que foi bastante tardio em comparação a outros países, principalmente a Europa e os Estados Unidos. Em 1993, Silveira e colaboradores publicaram os primeiros trabalhos, e posteriormente Brugnera e Pinheiro, em 1998. 
O termo Laser é a abreviatura da expressão inglesa Light Amplification by Stimulated Emission of Radiation, que significa amplificação de luz por emissão estimulada de radiação (Low e Reed, 2001). Embora Albert Eistein tenha delineado os princípios subjacentes à geração deste tipo de luz no início do século XX, foi somente em 1960 que Maiman produzui o primeiro feixe de luz Laser, e com base neste protótipo surgiram vários aparelhos.

A radiação gerada pelo Laser de uso terapêutico difere da radiação gerada por outras fontes, pois, segundo Schawlow (1995), a luz produzida pelo Laser é monocromática, isto é, os raios Lasers são de um comprimento de onda específico e único, portanto, tem uma freqüência definida. A coerência ocorre por não ter apenas o mesmo comprimento de onda como também a mesma fase, ou seja, os picos e as depressões dos campos elétricos e magnéticos ocorrem ao mesmo tempo; apesar da perda da coerência da radiação no interior dos tecidos, esta é absorvida pelas células, gerando alterações no seu metabolismo, tanto em tecidos superficiais como em profundos (Haczeki, 1989; Svaasand, 1990).

Ocorre também a colimação, em que os raios de luz produzidos pelos aparelhos são paralelos, praticamente inexistindo qualquer divergência da radiação emitida (Kitchen e Bazin, 1998).

O Laser pode ser classificado em dois grupos: o Laser cirúrgico de alta potência (HILT - Hight-Intensity-Laser Treatment) e Laser não cirúrgico de baixa potência (LILT - Low-Intensity-Laser Treatment).

A terapia com Laser de baixa potência incide sobre as reações não térmicas (atérmicas) da luz com o tecido, ocasionando efeitos fotoquímicos (Schaffer et al., 2000), ou seja, as radiações com baixa densidade de potência (DP) (de $0,01 \mathrm{w} / \mathrm{cm}^{2}$ a $1 \mathrm{w} / \mathrm{cm}^{2}$ ) e também baixa densidade de energia (DE) (de 1 a $10 \mathrm{~J} / \mathrm{cm}^{2}$ ) (Schindl et al., 2000) produz um pequeno e não significante aumento de temperatura, o qual não ultrapassa a $1^{\circ} \mathrm{C}$ (Karu, 1987). 
O efeito fotoquímico ocorre especialmente devido à presença de fotorreceptores sensíveis a determinados comprimentos de onda. A absorção desses fótons por biomoléculas intracelulares específicas produz estimulação ou inibição de atividade enzimática e de reações fotoquímicas. Então estas ações determinarão mudanças fotodinâmicas em cadeias complexas e moléculas básicas de processos fisiológicos com conotações terapêuticas (Karu, 1987).

Após incidir sobre uma superfície, a luz Laser pode refletir, transmitir, espalhar-se ou ser absorvida.

O tecido biológico é pouco homogêneo do ponto de vista óptico, assim, ao incidir sobre o tecido toda radiação se desdobra: uma parte é refletida e a outra é absorvida. A reflexão varia com o ângulo de incidência da luz e as propriedades ópticas do tecido. Anderson et al. (1981) comprovaram que a reflexão da pele é de 4-7\% quando se incide perpendicularmente variando para mais com o uso de pomadas, líquidos e secreção sebácea. Dessa forma, os fótons vão se distribuir de acordo com a absorção de cada estrutura, pois a função fotorreguladora determina qual comprimento de onda cada estrutura é capaz de absorver e, com isso, promover transformações nas atividades funcional e metabólica da célula.

A função fotorreguladora se dá em decorrência dos fotorreceptores, que são moléculas de variedade morfológica e que se encontram distribuídas nas células do organismo, como: flavoproteínas, porfirinas, tirosinas, aspargina. Estas moléculas interferem no metabolismo celular sem a necessidade de energia luminosa, mas se incidir sobre elas uma radiação com comprimento de onda específico são capazes de absorver os fótons da radiação e provocar mudanças no metabolismo celular (Schaffer et al., 2000).

De acordo com Karu (1987), a absorção é considerada uma das mais importantes funções, pois sem ela não seriam possíveis os efeitos fotobiológicos, ou seja, os efeitos clínicos. 
As respostas desencadeadas pela radiação Laser nos tecidos biológicos estão relacionadas ao comprimento de onda, à potência, à densidade de energia, ao regime de pulso, contínuo ou pulsado, e ao método de aplicação pontual ou varredura (Low e Reed, 2001).

Guirro e Guirro (2002) descreveram que a penetração do Laser será maior quanto maior for o comprimento de onda, e a potência indica a quantidade de energia transmitida na unidade de tempo.

Colls (1984) analisou um esquema para os critérios de dosagem para analgesia (de 2 a $4 \mathrm{~J} / \mathrm{cm}^{2}$ ), antiinflamatório (de 1 a $3 \mathrm{~J} / \mathrm{cm}^{2}$ ), cicatrizante (de 3 a $6 \mathrm{~J} / \mathrm{cm}^{2}$ ) e circulatório (de 1 a $3 \mathrm{~J} / \mathrm{cm}^{2}$ ) e, segundo Rigau (1996), o ideal é que a energia total não ultrapasse $40 \mathrm{~J} / \mathrm{cm}^{2}$.

Rigau (1996), em estudos feitos com ratos em laboratório, observou que o efeito do Laser sobre o processo cicatricial em tegumentos era dependente das doses e da frequência, de modo que em mais de 5 dias por semana obtinha-se um efeito negativo sobre a cicatrização. Para evitar somação de estímulos e consequente redução da efetividade, Veçoso (1993) sugere que seja intercalado ao menos 1 dia sem aplicação.

Conforme Guirro e Guirro (2002), as aplicações podem ser realizadas pelos métodos pontuais ou varredura. A varredura é indicada para os casos em que há perda da solução de continuidade, como as úlceras, onde o contato do emissor do Laser pode desencadear um processo doloroso ou facilitar a contaminação do tecido. A aplicação pela técnica de contato possibilita que o operador pressione a sonda de tratamento nos tecidos para uma maior penetração da radiação eletromagnética, ficando, assim, reduzida a atenuação da luz (Schindl et al., 2000).

Embora a radiação Laser de baixa potência não tenha a capacidade ionizante, isto é, não rompe ligações químicas, a sua propriedade de indução fotobiológica é capaz de provocar alterações primárias, sendo estas bioquímicas, bioelétricas e bioenergéticas nas células (Sattayut, 2000). 
No efeito bioquímico a energia absorvida pode atuar de duas maneiras: estimulando a liberação de substâncias pré-formadas, como a histamina, serotonina, bradicinina, ou modificando as relações enzimáticas normais, tanto no sentido de excitação como de inibição. Inúmeras investigações têm confirmado que o Laser exerce um estímulo na produção de ATP no interior das células, o que origina e promove a aceleração da mitose (Schaffer et al., 2000).

De acordo com Mester et al. (1985), o Laser de baixa intensidade acelera a divisão celular e além disso também observaram um aumento do número de leucócitos que participaram da fagocitose e maior síntese de colágeno pelos fibroblastos.

No efeito bioelétrico as células têm seu interior eletricamente negativo em relação ao seu exterior, e essa diferença de potencial devese à existência de diferentes concentrações de íons positivos ou negativos dentro ou fora da célula. Dessa forma, o efeito bioelétrico da radiação Laser se resume da seguinte maneira: "manutenção do potencial de membrana" (Guirro e Guirro, 2002).

Por último, o efeito bioenergético diz respeito à normalização energética que a radiação Laser proporciona ao bioplasma. $O$ aporte energético da radiação Laser tem a capacidade de normalizar o contingente energético que coexiste com o contingente físico dos indivíduos (Hecht, 1992).

Nos efeitos secundários ocorre o estímulo à microcirculação, que é proporcionado pela ação da radiação sobre o esfíncter pré-capilar. Em decorrência da liberação da histamina pela radiação Laser ocorre uma paralisação deste esfíncter, ocorrendo um aumento do fluxo sanguíneo (Silva et al., 1998).

O processo apresentado não se refere ao mesmo proporcionado pela administração de calor, e sim pelo aumento do metabolismo local (Veçoso, 1993). 
Com o aumento da produção de ATP, a velocidade mitótica também é aumentada, o que proporciona o aumento na velocidade de cicatrização e a melhora do trofismo nos tecidos, e, consequentemente, o estímulo ao trofismo celular (Rigau, 1996).

Assim, como consequência das alterações primárias e secundárias, a radiação Laser proporciona efeitos terapêuticos, como a ação analgésica, antiinflamatória, antiedematosa e cicatrizante (Silva et al.,1998). 


\section{MATERIAIS E METÓDOS}

A pesquisa foi aprovada pela Comissão de Ética para Análise de Projetos de Pesquisa - CAPPesp da Diretoria Clínica do Hospital das Clínicas e da Faculdade de Medicina da Universidade de São Paulo, com o protocolo número 0942/07.

Animais

Foram utilizados 30 ratos da linhagem Wistar, machos, pesando em média $\pm 280 \mathrm{~g}$, com 23 dias de idade, obtidos no Biotério Central da Faculdade de Medicina Veterinária da UNESP - Botucatu.

Os ratos foram mantidos no Biotério de Experimentação Animal do Laboratório de Biodinâmica do Departamento de Educação Física - IBUNESP -, Campus Rio Claro-SP, em gaiolas coletivas com no máximo cinco (5) animais. Estes foram alimentados com ração balanceada para roedores (Labina), com $23 \%$ de proteína, água ad libitum e com condições ambientais controladas (ciclo claro/escuro; 12/12 horas ambiente higienizado; temperatura média de $25^{\circ} \mathrm{C}$ e ventilação controlada).

Grupos Experimentais

Os ratos foram divididos aleatoriamente em 3 grupos assim descritos:

- Grupo Controle (GC) - 10 ratos que não foram submetidos à aplicação do Laser.

- Grupo 5 (G5) - 10 ratos que foram submetidos à aplicação do Laser, com a dose de $5 \mathrm{~J} / \mathrm{cm}^{2}$. 
- Grupo 15 (G15) - 10 ratos que foram submetidos à aplicação do Laser, com a dose de $15 \mathrm{~J} / \mathrm{cm}^{2}$.

Delimitação da área

De acordo com o protocolo experimental planejado, os animais foram pesados no início e no fim do experimento, e os joelhos foram tricotomizados antes do início do experimento. O Laser foi aplicado na face anterior, medial e lateral da epífise proximal da tíbia de cada rato.

\section{Equipamento de Laser}

Durante a aplicação experimental, utilizamos um aparelho de Laser AsGaAl, marca Bioset - Indústria de Tecnologia Eletrônica Ltda, de modo que antes de ser utilizado foi calibrado em Ophir Optronics-INC.

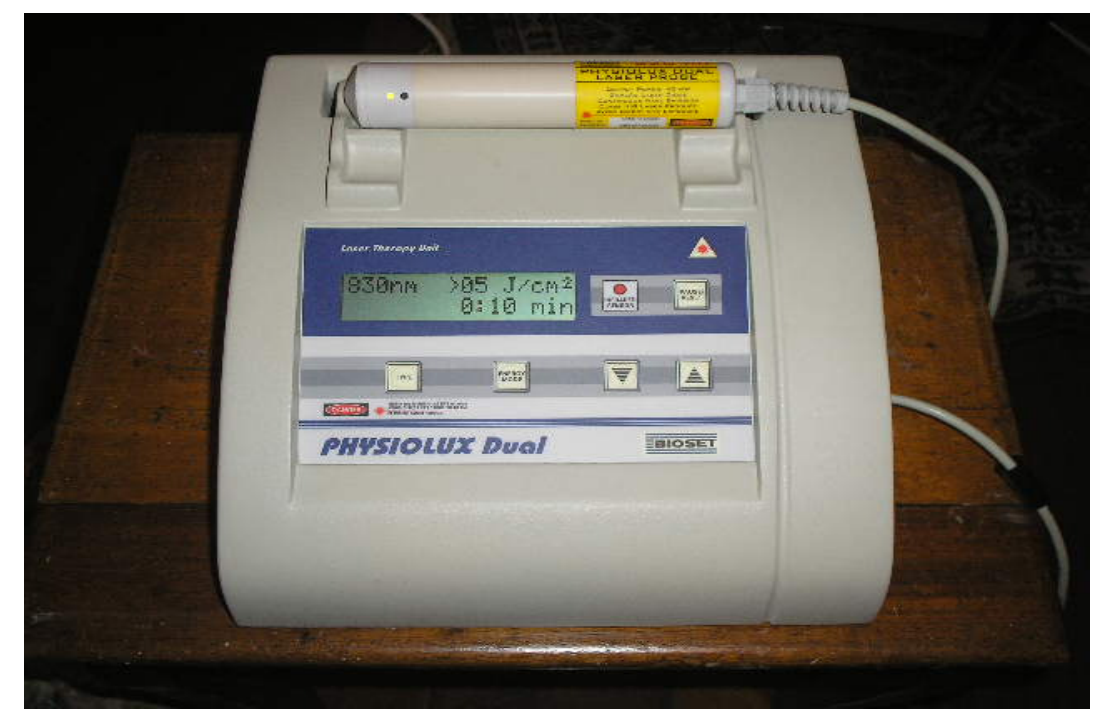

Figura 3 - Equipamento de Laser utilizado (Bioset) conforme Protocolo de Tratamento. 


\section{Protocolo de Tratamento}

Este aparelho de Laser AsGaAl tem comprimento de onda de 830 $\mathrm{nm}$, potência de pico de $0.04 \mathrm{~W}$, densidade de potência de $0.51 \mathrm{w} / \mathrm{cm}^{2}$; área do feixe de $0,078 \mathrm{~cm}^{2}$; diâmetro do feixe de $3 \mathrm{~mm}$; regime de pulso contínuo, aplicado pelo método pontual em 3 pontos por joelho.

Foi utilizada a densidade de energia de $5 \mathrm{~J} / \mathrm{cm}^{2}$ por ponto $(0,4 \mathrm{~J})$ com dose total de $15 \mathrm{~J} / \mathrm{cm}^{2}(1,2 \mathrm{~J})$, e com $15 \mathrm{~J} / \mathrm{cm}^{2}$ por ponto $(1,2 \mathrm{~J})$, com dose total de $45 \mathrm{~J} / \mathrm{cm}^{2}(3,6 \mathrm{~J})$. As aplicações ocorreram a cada 48 horas após a primeira aplicação, sendo realizadas 10 aplicações em dias alternados (David et al.,1996).

Durante a aplicação experimental, o emissor do Laser foi posicionado a $90^{\circ}$ em relação à superfície a ser irradiada para minimizar o índice de reflexão (Karu, 1998). No intervalo de cada aplicação foi realizada a assepsia da ponta da caneta com algodão estéril e álcool a $70 \%$.

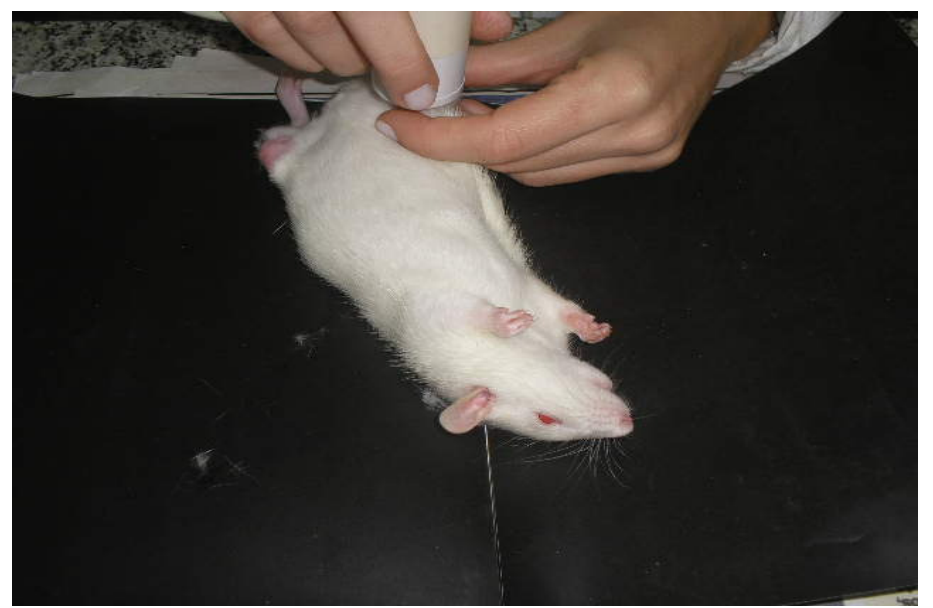

Figura 4 - Aplicação do Laser AsGaAl 830 nm. 
Coleta da Tíbia

No $21^{\circ}$ dia após a primeira aplicação e 24 horas após a última aplicação, os animais foram sacrificados,com dose letal de $200 \mathrm{mg} / \mathrm{Kg}$ de pentobarbital sódico.

As tíbias foram desarticuladas do joelho e do calcanhar e limpas dos tecidos moles associados para, então, serem deixadas em solução de formoldeídeo a $10 \%$ durante 72 horas para que ocorresse a fixação. Posteriormente as tíbias foram colocadas em solução de ácido nítrico a $5 \%$ para descalcificação. Após o período de descalcificação, o material foi desidratado em série ascendente de álcoois, diafanizados em xilol e incluídos em parafina de maneira a fornecerem cortes coronais da epífise.

Cortes e Técnicas Histológicas

Com auxílio de um micrótomo rotativo, foram realizados cortes longitudinais com espessura de $6 \mu \mathrm{m}$ da tíbia. Com uma amostra da cartilagem epifisária, estes cortes foram corados com HE (Hematoxilina Eosina) para que os elementos da cartilagem pudessem ser identificados e medidos. A partir destas lâminas realizou-se a documentação fotográfica em fotomicroscópio ZEISS.

Análise Histomorfométrica

A análise histomorfométrica foi realizada com auxílio de uma câmera acoplada ao microscópio e um monitor de vídeo, onde foi mensurada, com uma régua micrometrada marca Olimpus $(0,01 \mathrm{~mm})$, a espessura total da cartilagem, a contagem do número de condrócitos e a espessura das camadas de repouso, proliferativa, hipertrófica e degenerativa. 
Análise de imagem por Raio $X(R X)$

Antes da primeira e após a última aplicação do Laser, a tíbia dos animais foi radiografada com equipamento de Raio $X$ odontológico em incidência latero-lateral. Através das imagens radiográficas, foi possível verificar a presença e a integridade da cartilagem epifisária, que foi medida através do software AutoCAD®.

Foram realizadas cinco medidas da imagem da cartilagem epifisária para ser obtida a sua espessura média. Destas imagens ainda foram obtidos os comprimentos inicial e final da tíbia, ou seja, antes e depois do tratamento.

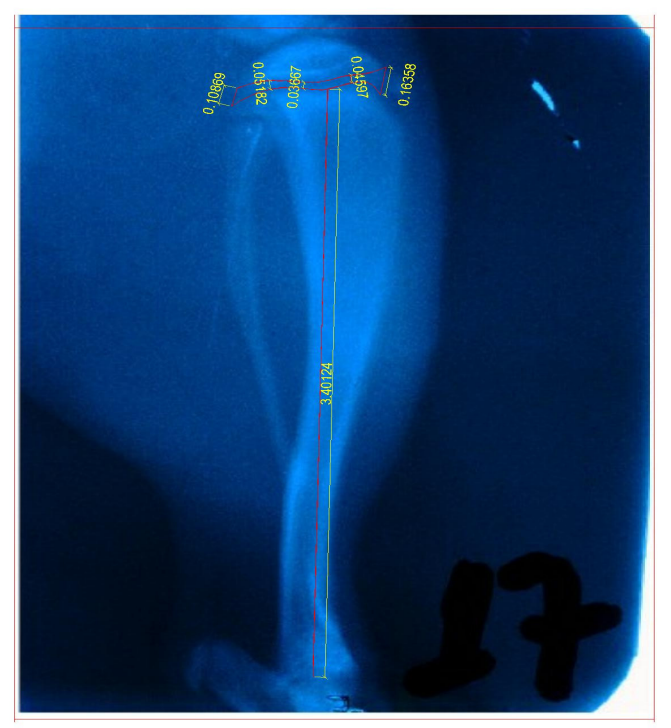

Figura 5 - Raio X da Cartligem Epifisária. 
Análise Estatística

Os resultados obtidos foram analisados intergrupos, com o teste de variância fatorial One-Way ANOVA com nível de significância considerado significativo para $\alpha<0,05$, seguido pelo teste de Tukey para verificar a significância entre os grupos. 


\section{RESULTADOS}

Análise Qualitativa e Histomorfométrica.

Em corte realizado no sentido frontal da tíbia foi possível observar a cartilagem epifisária em sua plenitude. Todas as camadas de células que compõem a cartilagem foram identificadas após terem sido coradas com H/E.

Em todos os grupos estudados pôde ser identificado, a partir do limite do osso da epífise próximal em direção ao osso da metáfise da tíbia, a camada de células em repouso, a camada de células proliferativas ou seriadas com suas colunas de células achatadas, seguidas da camada hipertrófica e logo depois da camada degenerativa.

As células da camada de condrócitos em repouso estão distribuídas em meio a um abundante interstício de matriz extracelular de cartilagem hialina. Estas, sob efeito hormonal e mecânico, multiplicam-se e formam grupos isogênicos de condrócitos surgidos a partir da multiplicação de um único condrócito da camada de condrócitos em repouso. A partir desta camada os condrócitos iniciam um processo de hipertrofia e aumentam de tamanho, tornando escassa a matriz extracelular desta camada. Estes condrócitos ficam, então, aprisionados em lacunas delimitadas por septos longitudinais cujas paredes se tornarão o suporte para a deposição de sais de $\mathrm{Ca}, \mathrm{K}$ e Hidroxiapatita. Nesta camada encontramos, dentro de uma lacuna, condrócitos mortos ou retraídos, por estarem em fase de degeneração. Ao degenerarem-se deixam espaços que formarão o tecido ósseo do osso em crescimento, os quais são invadidos pelas células da medula óssea contida na cavidade medular e por pequenos vasos sanguíneos (Figura 6).

Com base na medida linear das camadas de condrócitos, as células da cartilagem em repouso localizadas no limite da placa de crescimento 
com a epífise óssea apresentaram um pequeno número de condrócitos (Tabela 2) distribuídos na matriz extracelular. As células demonstraram aspecto sugestivo de pequena atividade mitótica e foram circundadas por um espaço lacunar reduzido, indicativo de pouca atividade celular.

$\mathrm{Na}$ camada proliferativa, grupos de condrócitos isogênicos formaram "pilhas" de células com atividade mitótica evidente e morfologia uniforme (Figuras 6,7,8), não sendo detectadas diferenças morfológicas no tamanho da pilha de condrócitos (Tabela 2) e tampouco no sentido de sua distribuição, que ocorre na direção do eixo longitudinal do osso quando comparados os grupos estudados.

$\mathrm{Na}$ camada hipertrófica, o grupo $15 \mathrm{~J}$ mostra espessura ligeiramente menor quando comparada à dos outros grupos (Tabela 1; Figuras 7 e 8). As camadas de condrócitos que formam a cartilagem de crescimento apresentaram espessura e morfologia uniformes quando comparamos a cartilagem epifisária do GC (Tabela 2).

A camada degenerativa mostrou a presença de grandes vacúolos e citoplasma retraído em todos os grupos, porém, no grupo G5 e G15, esta camada mostrou-se discretamente desorganizada, aumentada em número de condrócitos degenerados (Tabela 2), o que causou um consequente aumento de sua espessura. Este aumento pôde ser verificado pelo $\mathrm{RX}$ (Tabela 3) quando comparado ao grupo controle.

Este aumento foi mais evidente nos animais do grupo tratado com 15 $J$, porém não foi suficiente para causar qualquer alteração no comprimento final do osso (Tabela 3). 


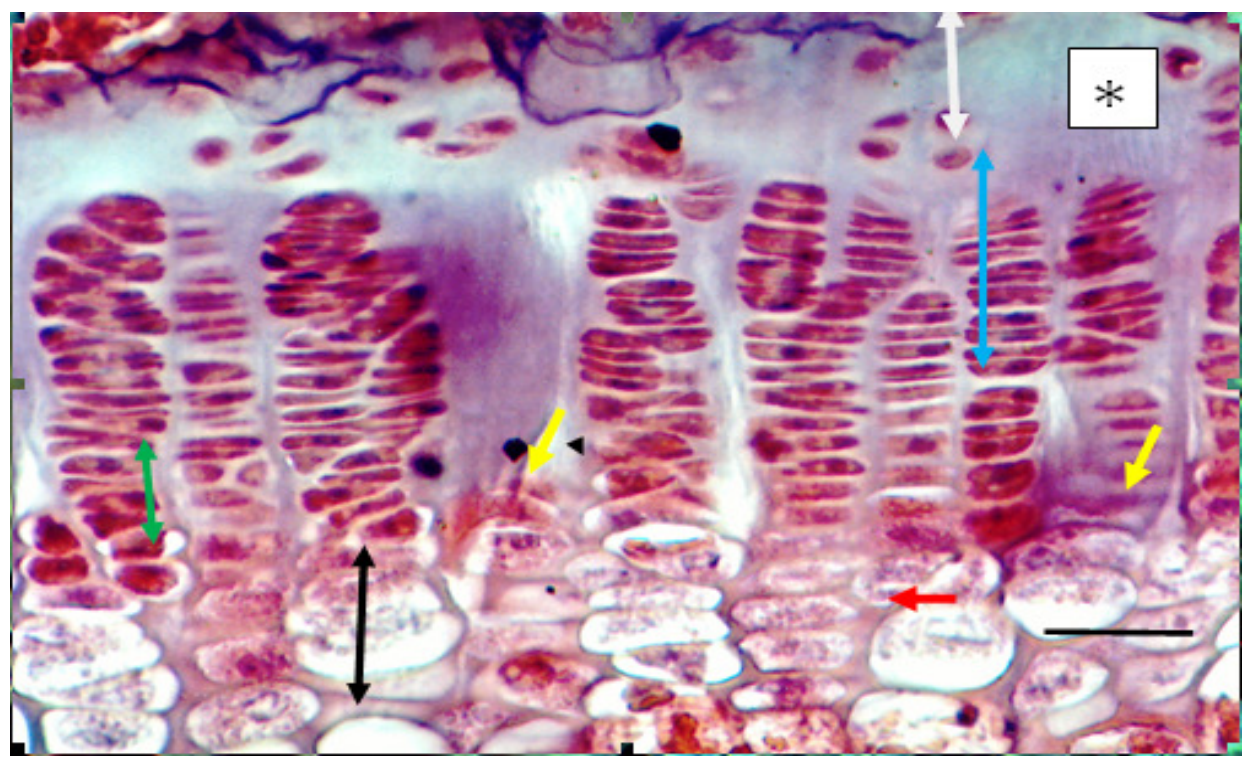

Figura 6 - Cartilagem epifisária de animal do GC, onde podem ser observadas as diferentes camadas de condrócitos. Camada de condrócitos em repouso (seta branca); camada de condrócitos proliferativos formando grupos isogênicos (seta azul); camada de condrócitos hipertróficos (seta verde); camada de condrócitos degenerativos (seta preta). Os condrócitos da camada hipertrófica são vacuolizados e preenchem toda a lacuna de matriz extracelular (seta amarela). Septos longitudinais (seta vermelha); e matriz extracelular (Asterisco). $\mathrm{H} / \mathrm{E}=25 \mu \mathrm{m}$.

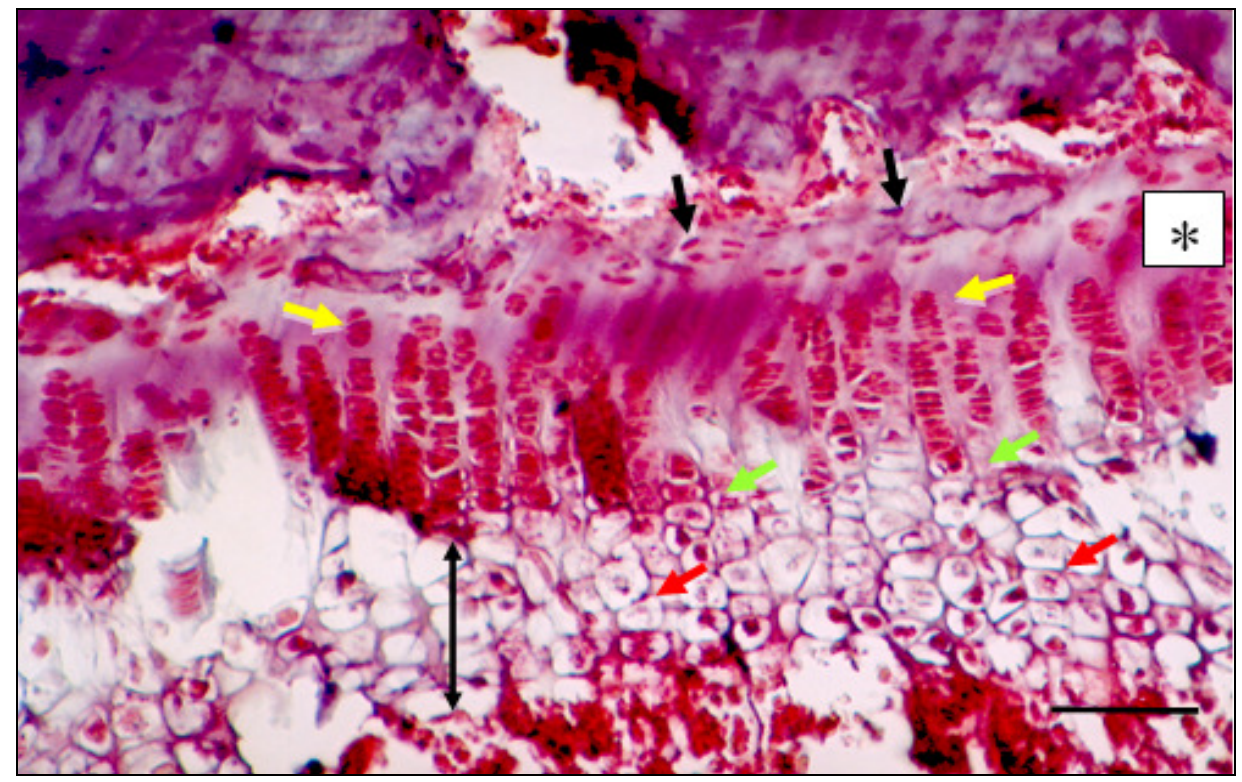

Figura 7 - Cartilagem epifisária de rato do grupo G5. Na camada de condrócitos em repouso pode ser observado um conjunto de células com pouca atividade mitótica (seta preta), circundado por abundante matriz extracelular (asterisco). A camada de condrócitos da camada proliferativa (seta amarela) começa a se multiplicar para dar origem aos grupos isogênicos, os quais estão distribuídos em matriz extracelular abundante no sentido longitudinal do osso. Camada de condrócitos hipertróficos envolvidos por escassa matriz. H/E. Barra $=60 \mu \mathrm{m}$. 


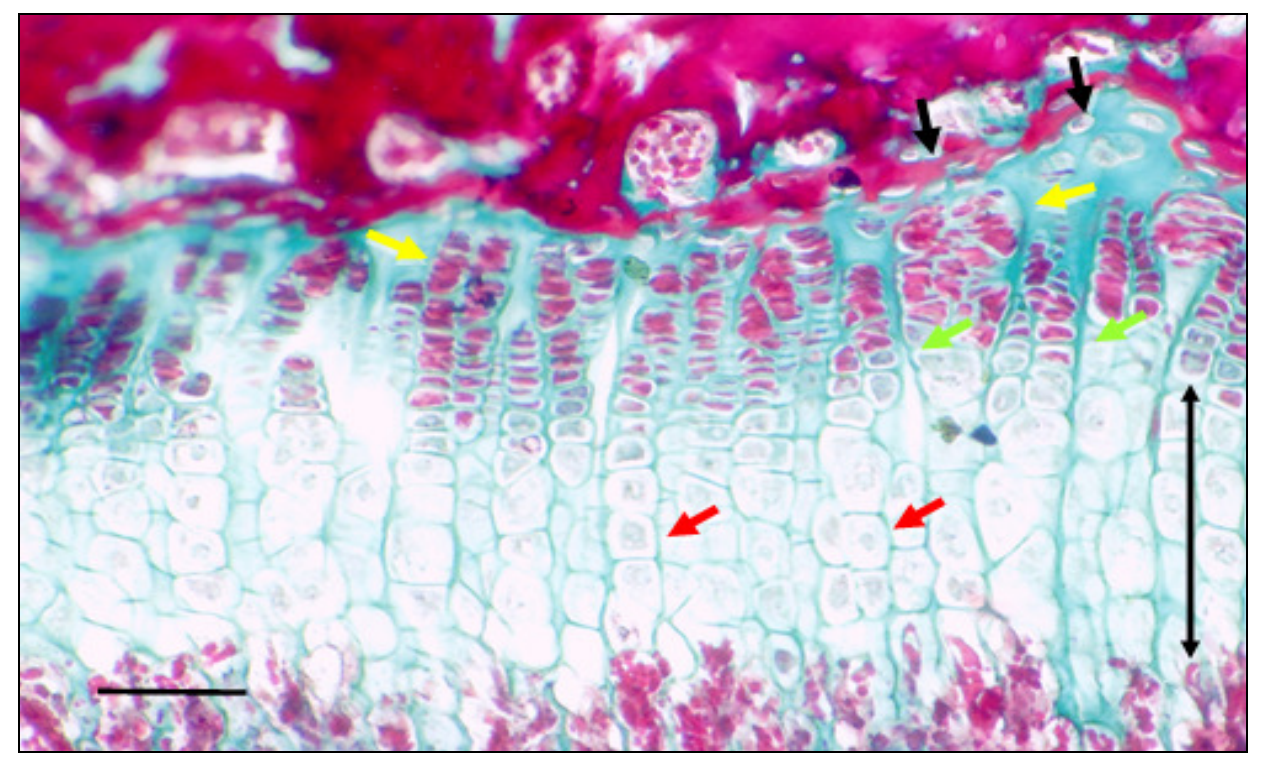

Figura 8 - Cartilagem epifisária de rato do grupo G15. Na camada de condrócitos em repouso é possível observar um conjunto de células com pouca atividade mitótica (seta preta) circundados por abundante matriz extracelular (seta amarela). A camada de condrócitos da camada proliferativa começa a se multiplicar para dar origem aos grupos isogênicos, os quais estão distribuídos em matriz extracelular abundante no sentido longitudinal do osso. Camada de condrócitos hipertróficos envolvidos por escassa matriz extracelular (seta verde); camada de condrócitos degenerativos (seta vermelha). H/E. Barra $=60 \mu \mathrm{m}$.

\section{Análise Quantitativa}

Os resultados obtidos foram analisados intergrupos, com o teste de variância fatorial One-Way ANOVA com nível de significância considerado significativo para $p<0,05$, seguido pelo teste de Tukey para verificar a significância entre os grupos. 
Tabela 1 - Média e desvio padrão $(\mu \mathrm{m})$ da medida das camadas de cartilagem em repouso, proliferativa, hipertrófica, degenerativa e espessura total da cartilagem epifisária após aplicação do Laser AsGaAl 830 nm.

\begin{tabular}{cccccc}
\hline Grupos & Repouso & Proliferativa & Hipertrófica & Degenerativa & Espessura \\
Camadas & & & & & \\
\hline $\mathrm{C}(\mathrm{n}=10)$ & $22,5 \pm 6,57^{\mathrm{A}}$ & $35,8 \pm 8,35^{\mathrm{A}}$ & $41,2 \pm 12,06^{\mathrm{A}}$ & $31 \pm 11,11^{\mathrm{A}}$ & $130,5 \pm 18,078^{\mathrm{A}}$ \\
$5 \mathrm{~J}(\mathrm{n}=10)$ & $18,9 \pm 5,83^{\mathrm{B}}$ & $35,4 \pm 7,62^{\mathrm{A}}$ & $36,8 \pm 8,91^{\mathrm{AB}}$ & $56 \pm 25,31^{\mathrm{B}}$ & $147,1 \pm 31,071^{\mathrm{B}}$ \\
$15 \mathrm{~J}(\mathrm{n}=10)$ & $18,5 \pm 6,06^{\mathrm{B}}$ & $32,6 \pm 10,11^{\mathrm{A}}$ & $35,9 \pm 9,83^{\mathrm{B}}$ & $71 \pm 36,36^{\mathrm{C}}$ & $158 \pm 37,22^{\mathrm{B}}$
\end{tabular}

Letras iguais na mesma coluna não apresentam diferença estatística $(p>0,05)$.

Letras diferentes na mesma coluna apresentam diferença estatística $(p<0,05)$.

Tabela 2 - Média e desvio padrão $(\mu \mathrm{m})$ do número de condrócitos das camadas de cartilagem em repouso, proliferativa, hipertrófica, degenerativa após aplicação do Laser AsGaAl $830 \mathrm{~nm}$.

\begin{tabular}{ccccc}
$\begin{array}{c}\text { Grupos } \\
\text { Camadas }\end{array}$ & Repouso & Proliferativa & Hipertrófica & Degenerativa \\
\hline $\mathrm{C}(\mathrm{n}=10)$ & $2.1 \pm 0.8^{\mathrm{A}}$ & $6.6 \pm 1.42^{\mathrm{A}}$ & $4.4 \pm 2.1^{\mathrm{A}}$ & $2.3 \pm 0.8^{\mathrm{A}}$ \\
$5 \mathrm{~J}(\mathrm{n}=10)$ & $2.3 \pm 0.68^{\mathrm{A}}$ & $6.9 \pm 1.72^{\mathrm{A}}$ & $5.3 \pm 1.15^{\mathrm{A}}$ & $5.8 \pm 1.13^{\mathrm{B}}$ \\
$15 \mathrm{~J}(\mathrm{n}=10)$ & $1.9 \pm 0.83^{\mathrm{A}}$ & $7.1 \pm 1.03^{\mathrm{A}}$ & $5.1 \pm 0.7^{\mathrm{A}}$ & $6.9 \pm 1.35^{\mathrm{B}}$
\end{tabular}

Letras iguais na mesma coluna não apresentam diferença estatística ( $p>0,05)$.

Letras diferentes na mesma coluna apresentam diferença estatística $(p<0,05)$.

Tabela 3 - Média e desvio padrão da espessura final e inicial da cartilagem epifisária e comprimento final da tíbia, medidas através da imagem de $\mathrm{RX}(\mathrm{em} \mu \mathrm{m})$, após aplicação do Laser AsGaAl $830 \mathrm{~nm}$.

\begin{tabular}{ccccc}
\hline Grupos & $\begin{array}{c}\text { Média } \\
\text { espessura } \\
\text { inicial }\end{array}$ & $\begin{array}{c}\text { Média } \\
\text { espessura } \\
\text { final }\end{array}$ & $\begin{array}{c}\text { Diferença da } \\
\text { espessura } \\
\text { inicial e final }\end{array}$ & $\begin{array}{c}\text { Comprimento da } \\
\text { Tíbia (cm) }\end{array}$ \\
\hline$C(n=10)$ & $136 \pm 0,02$ & $128 \pm 0,03$ & $-8^{A}$ & $3,36 \pm 0,21^{A}$ \\
$5 J(n=10)$ & $124 \pm 0,02$ & $128 \pm 0,03$ & $4^{B}$ & $3,58 \pm 0,12^{A}$ \\
$15 J(n=10)$ & $120 \pm 0,02$ & $152 \pm 0,04$ & $32^{C}$ & $3,69 \pm 0,16^{A}$ \\
\hline
\end{tabular}

Letras diferentes na mesma coluna apresentam diferença estatística $(p<0,05)$.

Letras iguais na mesma coluna não apresentam diferença estatística $(p>0,05)$. 


\section{DISCUSSÃo}

O Laser diodo de AsGaAl, com comprimento de onda de $830 \mathrm{~nm}$ e aplicado sobre a cartilagem epifisária, demonstrou através da análise histológica e pela imagem do $R X$ um aumento da espessura da cartilagem epifisária dos grupos G5 e G15 e um aumento no número de condrócitos do grupo G15.

As camadas da cartilagem tiveram comportamentos diferentes diante da aplicação da Laserterapia: a camada de repouso apresentou uma diminuição significativa da espessura quando comparados o GC com os grupos tratados. Na camada hipertrófica do grupo G15 ocorreu uma diminuição da espessura quando comparado ao GC. A camada degenerativa mostrou aumento da espessura nos grupos tratados, comparados ao GC e entre eles.

Este aumento da espessura da cartilagem não vem acompanhado de qualquer alteração no comprimento da tíbia, conforme a análise da imagem do RX.

Segundo lannotti (1990), a camada de repouso é composta por uma camada de condrócitos, cuja função está relacionada à reserva de nutrientes e substratos, como lipídios e glicogênio, e, por serem células ricas em retículo endoplasmático, são produtoras de proteínas. A diminuição da espessura desta camada nos grupos tratados com Laser, pode ter sido causada pelo aumento do metabolismo destas células que, ao serem estimuladas pelo Laser, passaram a consumir mais nutrientes da matriz extracelular para as atividades celulares. No entanto, este fato deve ser aprofundado em pesquisas futuras.

Estudos demonstram que o Laser provoca alteração no número de componentes da cadeia respiratória (citocromo, citocromo oxidase e flavina desidrogenase) por excitação de fotorreceptores ou cromóforos (Baxter, 1997). Também se sabe que ele pode produzir alterações metabólicas importantes que culminam em influenciar no nível do ciclo de 
nucleotídeo, componente envolvido na síntese de RNAm, um sinalizador de síntese de proteína (Peterson, 1984).

A camada proliferativa não sofreu alteração em nenhum dos grupos estudados, pois a função dos condrócitos desta camada está relacionada à produção de matriz extracelular com suas fibras de colágeno e outras substâncias próprias da matriz, além da produção de novos condrócitos. A proliferação de condrócitos é a única responsável pelo crescimento linear dos ossos longos (Brighton, 1987). Assim, acreditamos que o fato de obtermos tíbias com as mesmas dimensões nos três grupos pesquisados deve ser em função de esta camada não ter sido sensibilizada pelo tratamento com o Laser.

Utilizando US na epífise de crescimento, Lyon et al. (2003) observaram que a camada proliferativa sofreu desorganização, sendo possível observar que com doses altas $\left(2.2 \mathrm{~W} / \mathrm{cm}^{2}\right)$ ocorreram mudanças patológicas na epífise e na metáfise; enquanto doses baixas $\left(0.5 \mathrm{~W} / \mathrm{cm}^{2}\right)$ não alteraram a epífise. Ogurtan et al. (2002) utilizaram doses de 0.2 e $0.5 \mathrm{~W} / \mathrm{cm}^{2}$ e concluíram que não ocorreu fechamento parcial e total da epífise na região do carpo e que esta não sofreu deformidades.

Em estudo realizado com o Laser de alta potência $\left(\mathrm{CO}_{2}\right)$ em cartilagem epifisária de coelhos, Morein et al. (1978) demonstraram que o Laser aplicado diretamente sobre cartilagem epifisária prejudica a cartilagem seletivamente, porém, o osso adjacente não sofre alterações.

Dados clínicos mostram o efeito deletério do Laser de alta potência em crianças: Peterson e Wood (2001) relatam o caso de uma criança com dano tecidual de duas falanges epifisária distal, e, quando utilizado o Laser $\mathrm{CO}_{2}$ para ablação de verrugas, houve deformidade e encurtamento das digitais, tornando necessária a realização de osteotomia corretiva.

Nosso estudo mostrou diminuição da espessura da camada hipertrófica do grupo G15 tratado, o que pode estar relacionado a uma provável aceleração da fase de ossificação ocorrida nos septos quando 
estas células começaram a degenerar até a sua total desintegração. A lacuna deixada pela degeneração celular foi posteriormente sendo preenchida pela medula óssea que invadiu este espaço.

A medula óssea leva consigo osteoblastos e osteoclastos que trabalharam sincronicamente na reabsorção e na recomposição do osso, produzindo o que chamamos de remodelação. No caso dos grupos tratados, acreditamos que a invasão de osteoclastos e osteoblastos deva ter ocorrido mais lentamente, já que os espaços lacunares deixados pelos condrócitos se mantiveram intactos e vazios, mostrando aumento da espessura da camada degenerativa concomitante ao número de condrócitos degenerados nesta camada.

O fato de ter permanecido por mais tempo sem que a invasão da medula acontecesse deverá ser levantado em futuros trabalhos, que deverão abordar a formação destes septos e sua remodelação pelos osteoclatos e osteoblastos sob efeito da irradiação do Laser.

O aumento da espessura da cartilagem epifisária total dos grupos tratados com Laser pode ter ocorrido, segundo os dados coletados, devido, principalmente, ao aumento do número de condrócitos da camada degenerativa.

Torricelli et al. (2001) utilizaram o Laser AsGaAl para avaliar o efeito da bioestimulação na cartilagem in vitro e observaram que o Laser tem bom efeito bioestimulatório e não causa danos às células dos condrócitos.

Acreditamos que em nosso trabalho possa ter ocorrido um espessamento ou um aumento na densidade da matriz extracelular, o que dificulta e atrasa a ação dos osteoclastos e suas enzimas lisossomiais, responsáveis pela absorção dos septos transversos de cada coluna de condrócitos, permitindo que eles sejam, posteriormente, invadidos pelas células endoteliais, osteoblastos, osteoclastos e capilares, além das células próprias da medula óssea (hematopoiéticas). Este também é um fato que deve ser explorado em pesquisas futuras. 
O aumento da espessura da camada de cartilagem degenerativa pode ser um fator de risco para fraturas nesta região do osso, uma vez que o aumento de uma região óssea que não está completa e apropriadamente calcificada pode deixar o osso mais sujeito a lesões.

Novos estudos devem ser realizados variando os parâmetros dosimétricos (dose, comprimento de onda, tempo de tratamento e número de aplicações) para verificar possíveis alterações na cartilagem epifisária. 


\section{CONCLUSÃO}

Concluímos que o tratamento com Laser de AsGaAl $830 \mathrm{~nm}$ dentro dos parâmetros utilizados nesta pesquisa pode causar alteração na espessura da cartilagem epifisária e aumento no número de condrócitos na camada degenerativa. Estas alterações, no entanto, não foram suficientes para causar alteração no comprimento final do osso. 


\section{REFERÊNCIAS BIBLIOGRÁFICAS}

Anderson RR. Parrish JÁ. J Invest Dermatol.1981; 77(1): 13-9.

Baxter D. Therapeutic Laser. USA: Churchill Livingstone; 1997.

Baxter D. Laserterapia de baixa intensidade. Eletroterapia Prática Baseada em Evidências. 2003; 11.

Bright RW. Partial growth plate arrest: identification, classification, and results of treatment. Orthop Trans. 1982; 6: 65.

Brighton C. Struture and Function of the Growth Plate. Clin Orthop. 1978; 136: 22-32.

Brighton CT, Ray RD, Soble LW, et al. In vitro epiphyseal plate growth in various oxygen tensions. J. Bone Joint Surg. 1969; 1A: 1383-1396.

Brighton CT. Morphology and Biochenistry of the growth plate. Rheumatic Disease Clinics of North America. 1987; 13: 75-100.

Cheetham MJ, Young SR, Dyson M. Histological effects of $820 \mathrm{~nm}$ Laser irradiation on the healty growth plate of the rat. Laser Therapy. 1992; 4 (2): 56-64.

Coombe AR, Hunter MA. The effects of low level Laser irradiation on osteoblastic cells. Clin. Orthod. 2001; 4: 3-14.

Dallemagne MJ, Fabry C. Bone structure and metabolism. Ciba Foundation Symposium. London: Churchill; 1956.

Dângelo JG, Fattini CA. Anatomia humana sistêmica e segmentar. 2a ed. São Paulo: Atheneu; 1997. 
David R, Nissan M, Cohen I, Soundry M. Effect of low power He-Ne Laser on fracture healing in rats. Lasers Surg Med. 1996; 19: 458-464.

Douglas RC. Tratado de Fisiologia Aplicada a Ciências Médicas. 6a ed. 2006, 1243-1256.

Gartner LP, Hiatt JL. Tratado de Histologia em cores. Rio de Janeiro: Guanabara Koogan; 1999. 415p.

Gartner LP, Hiatt JL. Atalas Colorido de Histologia. 3a ed. Rio de Janeiro: Guanabara Koogan; 2002.

Gerard J, Derricson BH. Principles of anatomy and phsiology. 11a ed. New York; 2005.

Gomes LSM, Volpon JB. Estudo experimental do processo de reparação das Lesões Epifisárias Tipo III e IV de Salter \& Harris. Rev. Bras. Ortop. 1991. v. 26, p. 161.

Gur A, Cosut, A, Sarac AJ, Cevik R, Nas K, Uyar A. Efficacy of different therapy regimes of low-power Laser in painful osteoarthritis of the knee: a double and randomized controlled trial. Lasers Surg Med. 2003; 33: 330338.

Guyton AC, Hall JE. Tratado de fisiologia Médica. 9a ed. Rio de Janeiro: Guanabara Koogan; 1997.

Haczeki O, Tamura M. Near infrared quadruple wl. Spectrophotometry of the rat head. Adv.Exper. Med. Biol. 1989: 248.

Hecht J. The Laser guidebook. 2a ed. 1992. 498p.

Iannotti JP. Growth Plate Phsiology and Pathology. The Orthopedic Clinic of North America. 1990; 21: 1-17. 
Junqueira LC, Carneiro J. Histologia básica. 8a ed. Rio de Janeiro: Guanabara Koogan; 1995. p. 108-126.

Junqueira LC, Carneiro J. Histologia Básica. 9a ed. Rio de Janeiro: Guanabara, 1999. p.111-128.

Kaplan FS et al. Form e Function of Boné. In: Simon SR. Orthopaedic Basic Science. American Academy of Orthopaedic Surgeons, 1994.

Karu TI. Photobiological fundamental of lowpower Laser therapy. IEEE.J. QuanT Elect. 1987; 23: 1703.

Karu TI. The science of low-power Laser therapy. Amsterdan the Netherlands: Gordon and Beach Science Publishers; 1998.

Karu IT. Low-Power Laser Therapy. In: VoDinh T (ed.), Raton B. Biomedical Photonics Handbook. FL: CRC Press; 2003. p. 1-25.

Kember NF. Cell division in endochondral ossification: a study of cell proliferation in rat bones by the method of tritiated thymidine autoradiography. J. Bone Joint Surg. 1960; 42B: 824.

Kenwright J, Goodship AE Controlled Mechanical Stimulation in the treatment of tibial fractures. Clin Orthop. 1989; 241: 36-47.

Kimmel DB, Webster SS. A quantitative histological analysis of the growing long bone metaphsis. Calcif tissue Int. 1980; 32: 113-122.

Luger EJ, Rochkind S, Wollman Y, Galina K, Dekel S. Effect of low-power Laser irradiation on the mechanical properties of bone fracture healing in rats. Lasers in Surgery and Medicine. 1998; 22: 97-102.

Lyon R, Liu XC, Meier J. The effects of therapeutic vs. high-intensity ultrasound on the rabbit growth plate. J. Orthop. Res. 2003; 21: 865-871. 
Marieb EN, Hoehn K. Anatomy \& Physiology. 7a ed. San francisco; 2007.

Morein G, Gassner S, Kaplan I. Bone growth alteration resulting from application of $\mathrm{CO}_{2}$ Laser beam to the epiphyseal growth plates. Acta Orthop. Scand. 1978; 49: 244-248.

Navratil L, Kymplova. Contraindications in Noninvasive Laser Therapy: Truth and Fiction. Journal of Clinical Laser Medicine \& Surgery. 2002; 20: 341-343.

Nepola JV, Frederick DC, Baker JT. Effects of pulsed eletromagnetic field on bone healing in a rabbit tibial osteotomy model. $J$ Orthop Trauma. 2000; 14: 93-100.

Nicolau AR, Jorgetti V, Rigau J, Pacheco TTM, Reis ML, Zângaro AR. Effect of low-power GaAlAs Laser $(660 \mathrm{~nm})$ on boné structure and cell activity: an experimental animal study. Lasers Med Sci. 2003; 18: 89-94.

Ogurtan Z, Celik I, Izci C, Boydak M, Alkan F, Yilmaz K. Effect of Experimental Therapeutic Ultrasound on the Distal Antebrachial Growth Plates in One-Month-Old Rabbits. The Veterinary Journal. 2002; 164: 280 287.

Ostrum RF, et al. Bone injury, Regeneration and repair. In: Simon SR. Orthopaedic Basic Science. American Academy of Orthopaedic Surgeons. 1994.

Peterson HA. Partial Growth Plate Arrest and its treatment. Journal of Pediatric Orthopedics. 1984; 4: 246-258.

Peterson HA, Wood MB. Physeal Arrest Due to Laser Beam Damage in a Growing Child. Journal of Pediatric Orthopaedics. 2001; 21: 335-337. 
Pilla AA, Mount MA, Nasser PR, Khan SA. Non-invasive low intensity pulsed ultrasound accelerates bone healing in the rabbit. J. Orthop. Trauma. 1990; 4: 246-253.

Reed A, Low J. Electrotherapy Explained Principles and Pratice. 1997: 314-329.

Salter RB, Harris R. Injuries Involving the epiphseal plate. J. Bone Joint Surg. 1963; 45A.

Sattayut S, Huges F, Bradely P. 820nm gallium aluminum arsenide Iser modulation of prostaglandin E2 production in interleukin I stimulated myoblasts. Laser Therapy. 1999; 11: p. 8895.

Schaffer M, Bonel H, Sroka R, Achaffer PM, Busch M, Reiser M, Duhmke E. Effect of $780 \mathrm{~nm}$ diode Laser irradiation on blood microcirculation preliminary findings on time - dependent T1-weighted contrast enhanced magnetic resonance imaging (MRI). J. Photochem and Photobil. B. Biol. 2000; 54: 55-60.

Schawlow, AL. Principle of Laser Journal of Clin. Laser Med. Surgery. 1995; $13: 3$.

Schindl A, Schindl M, Pernerstorfer-Schon H, Schindl L. Low-intensity Laser therapy: a review. Journal of investigate medicine. 2000; 48, p. 312326.

Schott PCM, Gameiro VS. Fracturas e lesões epifisárias. In: Hebert SX, Renato. Ortopedia e traumatologia principios e prática. $2 a$ ed. Porto Alegre: ArtMed Editora; 2003. p.895-899.

Stevens A, Lowe J. Histologia Humana. 2a ed. São Paulo: Manole; 2001. $397 p$. 
Svaasand LO. Bioestimulation with-intensity Lasers physics or metaphysics? Nordisk Med. 1990: 105-172.

Tam G. Low Power Laser Therapy and Analgesic Action. Journal of Clinical Laser Medicine \& Surgery. 1999; 7: 29-33.

Torricelli P, Giavaresi G, Fini M, Guzzardella GA, Morrone G, Carpi A, Giardino R. Laser bioestimulation of cartilage: in vitro evaluation. Biomed Pharmacother. 2001; 22: 117-120.

Vaquero DH, Suarez JA. Fracturas de La rodilla en La edad de crecimiento. Curso de Verano, Universidad de Iviedo, jun. 1999.

Wiltink A, Nijweide PT, Oosterbaan WA. Effect of Therapeutic Ultrasound on Endochondral Ossification. Ultrasoun in Med \& Biol. 1995; 21: 121-127. 


\section{Apêndices}

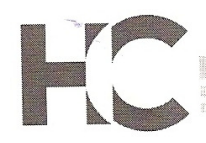

\section{APROVAÇÃO}

A Comissão de Ética para Análise de Projetos de Pesquisa - CAPPesq da Diretoria Clínica do Hospital das Clínicas e da Faculdade de Medicina da Universidade de São Paulo, em sessão de 24/10/2007, APROVOU o Protocolo de Pesquisa n 0942/07, intitulado: "INFLUÊNCIA DO LASER ASGAAL 830NM NA EPÍFISE DE CRESCIMENTO ÓSSEO EM RATOS." apresentado pelo Departamento de FISIOTERAPIA, FONOAUDIOLOGIA E TERAPIA OCUPACIONAL.

$$
\text { Cabe ao pesquisador elaborar e apresentar à }
$$
CAPPesq, os relatórios parciais e final sobre a pesquisa (Resolução do Conselho Nacional de Saúde $n^{\circ} 196$, de 10/10/1996, inciso IX.2, letra "c").

Pesquisador (a) Responsável: Dra. Raquel Aparecida Casarotto

Pesquisador (a) Executante: Marcela Dalla Costa Cressoni

CAPPesa, 06 de Novembro de 2007

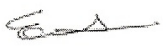

Prof. Dr. Eduardo Massad Presidente da Comissão de Ética para Análise de Projetos de Pesquisa 